\title{
Case Study as a Choice in Qualitative Methodology
}

\author{
Baboucarr Njie \& Soaib Asimiran
}

\begin{abstract}
The relegation of qualitative research to subordinate status decades ago has given way to its appreciation as a means of conducting studies that beg for deep thrust, humanistic adjustment and rich interpretation. Hence attention is now focused on when it should be used as opposed to relevance and credibility issues. This literature review argues to emphasize the place of qualitative research through its need and relevance before focusing on the case study method by unraveling its significance, what it does and when it is most apt for use in the qualitative research schema. In particular, it argues on the need to have three important components addressed in case studies to unearth a more holistic view: the process or practice, the interaction within such a process and the meaning of such interaction.

Keywords: Case Study, Qualitative, methodology, research
\end{abstract}

\section{Introduction}

It lies bare that the choice of the research method employed to conduct research is grounded strongly on what is sought to be known, the thrust from which it wishes to be known and the depth the issue is chosen to be dug. Qualitative methodology, just as implied in its name emphasizes on the underlying qualities of entities and processes and their implicit meanings. It is anchored on the appreciation of the sociological constructed nature of reality attaching the researcher in a positively rewarding manner to the research. A benefit to be derived from the researcher's participation in whatever capacity and degree is determined by their own resolve and commitment to not only unearth rich and useful information but to situate it in context through analysis for the best possible meaning and report.

\section{Qualitative methodology}

The debate on the nature of truth long engaged by scholars from both the qualitative and quantitative research paradigms has helped established the two methods as distinct choices of what one needs to inquire and not a contest of which is better or more credible. Quality inquiry is distinguished by its emphasis on holistic treatment of phenomena (Silverman, 2000) and has moved social research away from the common emphasis of cause and effect explanation as we used to know toward personal interpretation (Stake, 2010). Stake further unravels the epistemology of quality research as existential( nondeterministic) and constructivist and further emphasizes the correlation of the two as leaning on the principle that "phenomena are intricately related to many coincidental actions and that understanding them requires a wide sweep of contexts: temporal and spatial, historical, political, economic, cultural, social, personal". This brings to light the humanistic virtues of qualitative research as well as the interpretative approach which is needed to understand certain situations, settings and the complexities between relations which are way too important and way too intricate to be understood by mere foraging through random sampling or the calculation of means and modesof results.

An essential interest in qualitative research is the revelation of meaning buried in the nature of reality as understood and interpreted by people. Therefore how people add up or make sense of reality combined with their underlying suppositions that determine their behaviour is of paramount significance to researchers following the qualitative research trajectory. Denzin\&Lincoln(2004) captures this concept appositely as follows:

"Qualitative research is multi-method in focus, involving an interpretive, naturalistic approach to its subject matter. This means that qualitative researchers study things in their natural settings, attempting to make sense of, or interpret phenomena, in terms of the meanings people bring to them. Qualitative research involves the studied use and collection of a variety of empirical materials... that describe routine and problematic moments and meanings in individuals' lives."

The qualitative method is typically used on purpose in research. It is used specifically to unravel a complex phenomenon or one with little information about. Leedy\&Ormrod (2005) indicate that qualitative research "is definitely not the approach to take if you are looking for quick results and easy answers". It involves enthusiasm and the determination to dig deep to understand a situation or process and often need a longer time and further inquiry to better understand a situation through observation, interviews and further follow up sessions. Hence qualitative research is worth the effort and voluminous amount of time needed to conduct it to work loose complex phenomenon with rich details that cannot be amassed in research methods that rely on figures and absolutes. It portrays that other dimension deep rooted in thoughts and not easily represented on scales and averages, that underlying meaning unearthed through the genre of thorough questioning, 
interaction and observation whose choice is informed by the depth of what the research hopes to reveal especially the meanings and the relationship between situations and settings. Mason (2002) vividly summarizes the purpose of qualitative research thus:

"Through qualitative research we can explore a wide array of dimensions of the social world, including the texture and weave of everyday life, the understandings, experiences and imaginings of our research participants, the ways that social processes, institutions, discourses or relationships work and the significance of the meanings that they generate"

Peshkin (1993) specifies the following purpose that qualitative research serves: Description, interpretation, verification and evaluation. He asserts that in the descriptive sense qualitative research reveals the nature of a situation, setting or process; in the interpretative sense it helps in gaining new insights, concepts and discover problems that exists in a given situation; in the verification setting it helps experiment certain assumptions and in the evaluative sense it helps provide the means of judging the effectiveness of particular practices, innovations and processes. The Qualitative research paradigm in the context of the above mentioned four purposes is aptly a holistic method of inquiry that can delve into a phenomenon of the sort that seeks to unravel the lived experience of the quality assurance systems in this study. To unravel a well understood study of quality assurance in the higher education institutes, all the four purposes explained by Peshkin will be involved as follows: A description is required to disclose the system(s) of quality assurance in place while an interpretation is needed to get in depth knowledge of what prevails and the problems encountered; in the verification and evaluation phases views of the important players are sought to bear out the set plans as against the practical realities on the ground as well as an assessment of the overall picture to inform policy on the current situation and its future sustainability.

Qualitative research is generic and needs a direction which is mainly decided by the specific aim and type of study one chooses to conduct to arrive at a result. The Case study is one such direction which is prompted by the need to thrust deep into a specific unit, person, program or institution for a greater understanding which would not have been possible through other means.

\section{The Case Study}

Various genres of Qualitative research abound each specific to the context and nature of research that one intends to conduct. The case study, one such type, is generally a very illustrious category used by researchers. Its focus is to dig out the characteristics of a particular entity and its key distinguishable attributes include focus on a single unit, in depth description of a phenomenon, anchored on real live scenarios and uses multiple data collection methods. Specifically the case study method of qualitative research would be used for this study. A case study is a common framework for conducting qualitative research (Stake, 2000). A case study is depicted as a phenomenon of some sort occurring in a bounded context (Miles \&Huberman 1994). Yin (2003) offers a more detailed and technical definition of case studies as an empirical inquiry that investigates a contemporary phenomenon within its real-life context, especially when the boundaries between phenomenon and context are not clearly evident.

Hartley (2004) states that case study research "consists of a detailed investigation, often with data collected over a period of time, of phenomena, within their context," with the aim being "to provide an analysis of the context and processes which illuminate the theoretical issues being studied". Yin (2003) further posits that in a case study a "how" or "why" question is being asked regarding a contemporary set of events which the investigator has little or no control at all. The purpose of using the case study is to get in-depth details as much as possible about an event, person or process. Thick description (Merriam, 1998 \&Geertz, 1973) when systematically analyzed yields a valuable understanding and explanation of a process. Inquiries that require the understanding of the meaning of certain phenomenon and events, especially when processes are involved benefit more from using the qualitative research methods in general and the case study in particular to arrive at results that are exhaustive, rich in depth and information.

It is worthy of note that while the need to dig deep into an event, issue, person or process defies other methods in favor of the case study, achieving these is solely anchored on the tact, resilience and gusto of the researcher during the research process. The ability to bring out the rich humane attribute of the case study method is also stronglycontingent on the researcher's skill and thirst to do so. As stake (2005) writes "if case study research is more humane or in some ways transcendent it is because the researchers are so not because of the methods". The Case study concentrates on the experiential knowledge of the case and close attention to the influence of its social, political and other context which can only be dug out by experience and tact by the researcher of a level satisfactory to convince respondents or interviewees to respond appropriately.

\section{Typology of Case Study}

The Case study has often been categorized within related attributes but mostly with diverse numerical categories such as the three or six type classification.Most of the classifications cut across major themes and as 
such a lot of similarities can be traced to the typologies. For instance White (1992) categorized social science casework according to three purposes: case studies for identity, explanation, or control. Stake (1995) on the other hand comprehensively categorize case study into three types: intrinsic, instrumental and multiple case study.He regards a case intrinsic when it is zealously focused on a unit, person or institutional and relies exclusively on the living account of this group. Intrinsic case study is resorted to when one wants better understanding of a particular case and is within all its particularity and ordinariness a case of interest. The researcher thus suppresses other curiosities and focuses primarily on the stories and accounts of those "living the case" to be teased out. He describes a case as an instrumental when "a case is examined mainly to provide insight into an issue or to redraw a generalization". The case in this type is presumed to be of secondary interest and plays a supportive role by facilitating understanding of something else. In other words the case in this type is used as a means or an anchor for the purpose of elucidating the other interest strewn within or about it. He calls a case study multiple when a number of cases are jointly studied to investigate a phenomena, institution, person, population or entity.

\section{Justification for use of the Case study}

Stake (1994) tersely argues that a "case study is not a methodological choice, but a choice of [the] object to be studied". Thus the Case study is necessitated by the specificity of the case under investigated which is informed by its boundedness. ACase study is a type of qualitative research in which in-depth data are gathered relative to a single individual, program, or event for the purpose of learning more about an unknown or poorly understood situation (leedy\&Ormrod, 2005). Such distinctively clearly tells it out from other similar research methods which share some common platforms like the case study such as single subject experiments or phenomenology because the case study looks beyond a limited number of behaviors to the entire range and also links the relationships of such behaviors to both the subject history as well as the environment. The Merriam Webster's dictionary (2009) more aptly defines the case study as "an intensive analysis of an individual unit (as a person or community) stressing developmental factors in relation to environment". The case study therefore does a holistic inquiry by looking at the process or practice, the interaction within such a process and the meaning of such interaction for a more generic understanding of the case under study. According to Yin (2003) "the distinctive need for case studies arises out of the desire to understand complex social phenomena" for the reason that "the case study method allows investigators to retain the holistic and meaningful characteristics of real-life events,".

The focus on a unit is evidently a trait of a Case study and therefore distinctions characteristic of a unit and how this is factored into the research by approaching it with openness and acceptance is the advantage of using Case studies for research dealing with such areas. Yin (2003) captures the concept very well in his description of the case study method by relating it thus:

"The case study inquiry copes with the technically distinctive situation in which there will be many more variables of interest than data points, and as one result relies on multiple sources of evidence, with data needing to converge in a triangulating fashion, and as another result benefits from the prior development of theoretical propositions to guide data collection and analysis".

\section{Binding the Case}

The case study is a demarcation of a group, area or a situation for the purposes of concentrating intrinsically on it to understand and explain how it is living its case of interest. Hence the issue of binding the case is significant in that it helps put parameters to the case which enables the type of concentration or focus needed to bring to light the issues that are at play within the case. Most importantly binding the case avoidsthe ambiguity of "biting too much" and the difficulty of concentrating and analyzing large areas and volumes of information. Various scholars have suggested how to bind cases with some harping on the spatial, contextual or time binding. Baxter and Jack (2008) in particular recommend binding the case in order to avoid making the scope of research too broad, and suggest three ways to how to do it:

(a) by time and place (Creswell, 2003);

(b) time and activity (Stake 1995); and

(c) by definition and context (Miles \&Huberman, 1994)

\section{Data Collection and Qualitative Sampling Process}

Data Collection in Case study is one of the most significant activities in the process because the richness and depth of what will be eventually known is contingent on the craft and effectiveness of the data collection method in uncovering relevant details about the situation. In case study six major sources identified by researchers (Yin, 1994; Stake, 1995;Leedy \& Ormrod,2005) are Direct observation; Interview; Documents; Archival Records; Physical Artifacts and Participant observation. One or all of the sources could be used depending on the relevance and nature of the case. 
In Qualitative research the notion of sampling to be engaged is determined by the type of information the researcher wishes to obtain and which category of people and documents or which area(s) would be most suited to obtain it from. The size of the sample is not an important issue" (Schreiber \&Asner-Self, 2011) and overbearingly focused on as in quantitative research because the depth and quality of information obtained, its richness in unearthing clearer views of a particular situation or process is considered more prominent than the numbers. Schreiber \&Asner (2011) further explains that it is not as if potential participants cannot be randomly sampled in qualitative research but rather random sampling is not the modal sampling technique in such type of research as some aspects are potentially more important in the sampling process than random selection. Hence focus is rather on the sample that gives the best and the most in-depth information that the researcher seeks and since a careful selection of where information is best gotten often yields more information relevant to unearthing the questions that are asked in qualitative research, purposive sampling and the relevant number(s) involved are much more revered.

When it comes to sample size as earlier alluded to, the sample size is considered less important in as much the depth and richness of the research is covered by one or the very few sample size characteristic of the qualitative genre. Notwithstanding, generic rules of thumb of the sampling size in qualitative research characterized by the specific paradigm has been proposed. Kruger (1988) and Morse (1994) proposed at least one individual in a case study as indicated in the table immediately following. However due to the quest for rich data from units within the framework of the individual, unit or institution to be studied more than one individual could be used as the researcher deem fit. The amount of people used as already highlighted just adds to the depth and thoroughness of the information that is being looked and would not justify the generalization of the results judging the context specific and boundedness of the case study genre of qualitative research.

\section{Table}

Rules of thumb for Qualitative sample size

\begin{tabular}{|l|l|}
\hline Basic Study Type & Rule of Thumb \\
\hline Ethnography & $30-50$ interviews \\
\hline Case Study & At least one, but can be more \\
\hline Phenomenology & Six participants \\
\hline Grounded Theory & $30-50$ interviews \\
\hline Focus Groups & Seven to ten per group or more groups per each strata of interest \\
\hline
\end{tabular}

Source: Schreiber \&Asner-self (2011) quoting Kruger (1988); Morse (1994)

\section{On the "wholeness" of Case Study}

A Case study just as its name suggest is an embodiment of details about the subject matter under study. This is why the importance of drawing boundaries, "boundedness" as is commonly referred, is emphasized. The boundaries are clearly defined and declared from the onset of the study to enable the type of necessary attention and the collection of all the minutiae needed to arrive at interpretations and conclusions rich in details reflective of the case. Such an act of defining the boundaries,scooping out all details within the defined boundary and living the importance of knotting the details together in the final results isthe epitome of the case study exemplar.

After laying emphasis on the boundaries which swathes the case, it is essential to focus on the next significant activities which must be exhausted to ensure that the case undergoes the rigor of digging deep to unravel rich results. The first is the process or practice. This represents the causal activities that rouse the interaction between people within the case. Hence its importance and the need to explore how it takes places from what is laid down as policy to how this is translated into action in the routine and daily activities. The process or practice in the case is the defining activity, the core so to speak around which all other emergent activities are derived. The process or the practice is the basis for the activities of the case.

The second significant activity worth concentrating is the interaction within the process or practice. This defines all the important behaviors in regards to the activity. The reactions, acceptance, resistance, perceptions and the consequences of all these are embedded within the interaction of the process or practice. Understanding the interaction in detail from the levels, the times and the intensity are all crucially significant in the case study as these represent the action levels of the case. Understanding the case as it is in its natural setting is totally dependent on this interaction and how well it is dug and understood by the researcher. 
Figure

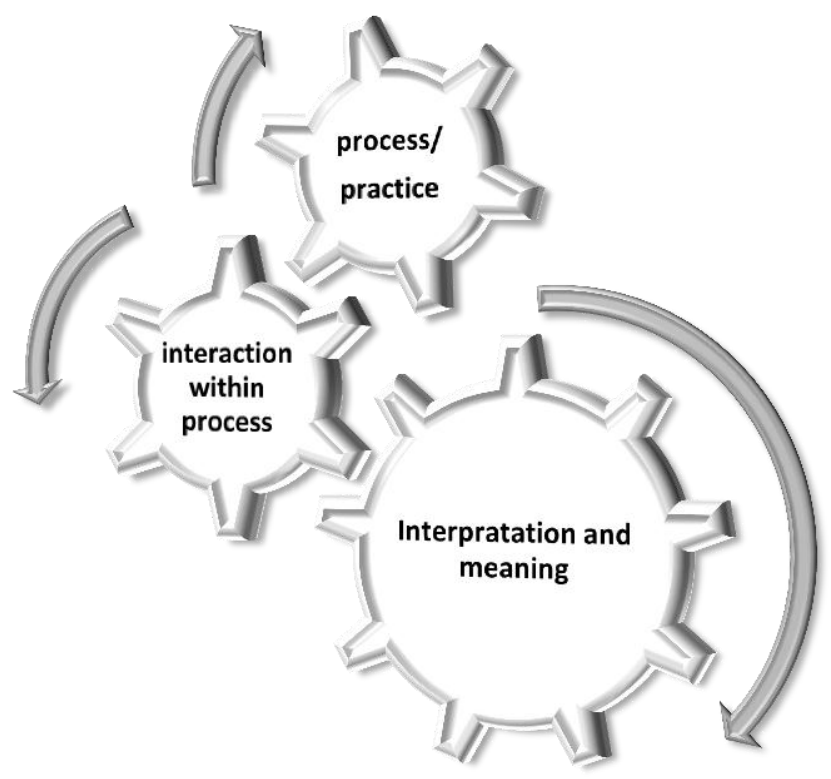

3 prime tasks in case studies

Next is the third level which tethers the process or practice as pronouncements and policies and the interaction in its entirety to enable telling a tangible story from the case - one backed by evidence, logical flow and acceptable patterns emerging from the case. This requires a great deal of thoroughness and enthusiasm from the researcher and the process also heavily relies on the richness of the information gathered on the process and the interaction. Building the meaning is like illustrating a picture as seen for other people to understand how it is. Thus the extent to which this understood would depend so much on how the illustration is made to help the cause. Usually the clearer in the use of simple language the better and the more the readers would be able to join into the understanding of the case being described.

\section{Conclusions}

A case study is an interesting approach to consider when a researcher is motivated to expend time and effort to a situation, area, program, a group or person with the aim of answering the "how" and "why" conundrums. As highlighted earlier it is not a simple approach that can be worked immediately for answers. It beseeches a lot of time, patient, and energy to work loose complex issues to knit together an explanation worthy of a studious finding.

\section{References}

[1]. Baxter, P. \& Jack, S. (2008) Qualitative case study methodology: Study design and implementation for novice researchers. The Qualitative Report, 13 (4), p.p.544-559.

[2]. Creswell, J.W. (2003). Research design. Qualitative, quantitative and mixed methods approaches. Thousand Oaks, CA: Sage.

[3]. Denzin, N.K. \& Lincoln, Y. S.(2004) Handbook of Qualitative Research. Thousand Oaks: Sage

[4]. Geertz, C. (1973). Thick description: Towards an interpretive theory of culture. In Clifford Geertz (Ed.), The interpretation of cultures (pp.3-32). New York: Basic Books.

[5]. Hartley, J. (2004). Case study research. In Catherine Cassell\& Gillian Symon (Eds.), Essential guide to qualitative methods in organizational research (pp.323-333). London: Sage.

[6]. Leedy, P., Ormrod, J.E.(2005): Prcatical Research . Planning and Design $8^{\text {th }}$ Edition.

[7]. Mason, J.(2002)Qualitative Researching. London: Sage

[8]. Merriam, S. B. (1998). Qualitative research and case study applications in education. San Francisco: Jossey-Bass Publishers.

[9]. Merriam-Webster Online Dictionary.http://www.merriam-webster.com/dictionary/case+study (accessed December 27, 2011).

[10]. Miles, M. B., \&Huberman, A. M. (1994). Qualitative data analysis: An expanded source book. 2nd ed. Thousand Oaks, CA: Sage.

[11]. Morse, J.M. (1994) Designing funded qualitative research. In N.K. Denzin and Y.S. Lincoln (eds) Handbook of Qualitative Research (pp. 220_235). Thousand Oaks, CA: Sage.

[12]. Peshkin, A.(1993) The Goodness of Qualitative Research. Educational Researcher, 22(2), 23-29

[13]. Schreiber, J.B. \&Asner-Self, K.(2011). Educational Research. Wiley.

[14]. Silverman, D. (2000). Analyzing talk and text. In N. K. Denzin\&. Y. S. Lincoln (Eds), Handbook of Qualitative Research (2nd ed., PP. 821-834). NewburyPark, CA- Sage.

[15]. Stake R.E.(2010) Qualitative Research: Studying How Things Work, Guilford Press

[16]. Stake, R. E.; Denzin, Norman K. (Ed); Lincoln, Yvonna S. (Ed), (2005). The Sage handbook of qualitative research (3rd ed.). , (pp. 443-466). Thousand Oaks, CA: Sage 
[17]. Stake R.E (2000) „Case Studies “ Ch.16 of Denzin and Lincoln (ed) Handbook of Qualitative Research 2nd edition, Sage

[18]. Stake, R. E. (1995). The art of case study research. Thousand Oaks, CA: Sage.

[19]. Stake, R.E. (1994). Case Studies, in N.K. Denzin and Y. Lincoln (eds). Handbook ofQualitative Research. California: Sage Publications, 236-47.

[20]. White, H. C. (1992). Cases are for identity, for exploration, or for Control for. In C.C Ragina\& H, S. Becker (Eds), What is a Case? Exploring the Foundations of Social Inquiry (pp.83-104). Cambridge, UK: Cambridge University Press

[21]. Yin, R. K. (2003). Case study research: Design and methods (3rd ed.). Thousand Oaks, CA: Sage.

[22]. Yin, R.K. (1994). Case Study Research - Design and Methods 2ND Edition. California, Sage Publications 